\title{
Morphometric Characteristics of C1-C2 Vertebrae to Perform Anterior Transarticular Crossing Screw Fixation
}

\author{
Kagan TUN¹, Berker CEMIL², Emre Cemal GOKCE ${ }^{3}$ \\ ${ }^{1}$ Acibadem University, Eskisehir Acibadem Hospital, Department of Neurosurgery, Eskisehir, Turkey \\ ${ }^{2}$ Private Practice, Neurosurgeon, Ankara, Turkey \\ ${ }^{3}$ Dr. Abdurrahman Yurtaslan Oncology Education and Research Hospital, Department of Neurosurgery, Ankara, Turkey
}

\section{ABSTRACT}

AIM: In unique clinical situations where C1-C2 posterior fixation is not available or has previously failed, an anterior transarticular screw (ATAS) may be a viable alternative. However, there are no previous reports that investigate possible screw angles, screw entry points, and screw length based on computed tomography (CT) multiplanar reconstruction images in Turkish patients. The aim of this study was to determine the morphometric characteristics C1-C2 vertebrae in order to perform anterior transarticular crossing screw fixation.

MATERIAL and METHODS: Patients who underwent a complete CT scan of the cervical spine for causes other than an investigation of cervical spine malformation or congenital anomaly between the years 2013 and 2015 were included in this study. The anterior transarticular C1-C2 screw angles, screw entry point, and screw length were measured on coronal and sagittal CT multiplanar reconstruction images.

RESULTS: Twenty-five male and 14 female patients were included in the study. The mean maximum screw angle for ATAS was found to be $41.18^{\circ} \pm 4.49^{\circ}$. The minimum and maximum screw lengths were $27.46 \pm 3.39 \mathrm{~mm}$ and $28.46 \pm 3.60 \mathrm{~mm}$, respectively.

CONCLUSION: Preoperatively, performing a calculation of the possible screw angles, screw entry point, and screw length based on CT multiplanar reconstruction images for ATAS is a safe and applicable method. In cases in which ATAS fixation across the atlantoaxial joint procedure should be performed without performing a measurement, a screw angle not more than $41.18^{\circ} \pm 4.49^{\circ}$ on the coronal plane does not damage the vertebral artery. Furthermore, using screws shorter than $28.46 \pm 3.60 \mathrm{~mm}$ doesn’t purchase the atlantoaxial joint.

KEYWORDS: Atlantoaxial joint, Computed tomography, Morphometry, Transarticular screw

\section{INTRODUCTION}

A nterior transarticular screw (ATAS) fixation is a welldefined technique alternative to posterior approach in the area of the first three vertebrae $(1,3,5,14,18,21,24)$. ATAS fixation for atlantoaxial instability was first described by Barbour (5) in 1971. Then, Lu et al. (17) performed an anatomical study about this topic in 1998. There had been no further studies on the topic up to 2003. In 2003, Reindl et al. (18) studied a technique that was included a standard Smith-
Robinson approach. After 2 years, a biomechanical study was performed by the same team and confirmed the effectiveness of this technique in atlantoaxial stabilization (19). Finally, some modifications in techniques of the minimally invasive surgery or percutaneous surgical procedures have been presented $(12,14,16,21)$.

Since the introduction of this procedure (5), different trajectories for single $(3,5,17,18)$ or double facet screws $(14,17,21,24)$ have been reported in the literature. The open 
surgery was performed at the entry point that was set at just below the sulcus of the anterior $\mathrm{C} 2$ corpus. This point was located at the mid-point of the C2 vertebra corpus and the medial third of the C1-C2 facet joint. The screw was inserted into the $\mathrm{C} 2$ body $20^{\circ}$ medially on the anteroposterior view and $30^{\circ}$ cephalic on the lateral view, crossing the atlantoaxial joint just anterior to the midpoint (19).

Although screw entry points can be recognized relatively easily during surgery due to the fact that they are visible or palpable, to evaluate both the screw cutout and the true position of the screw inside the bony structures may be difficult. However, the ideal trajectories for the use of ATAS fixation across the atlantoaxial joint on Turkish patients have not previously been measured on computed tomography (CT) landmarks. Therefore, the aim of the present study was to determine the possible screw angles, screw entry point, and screw length according to three-dimensional CT images.

\section{MATERIAL and METHODS}

Thirty-nine consecutive cervical spine CT scans were obtained between the years 2013 and 2015. Patients were selected from adults presenting to Acibadem Eskisehir Hospital for the treatment of non-cervical spine conditions. The inclusion criteria of the patients were age ranging from 18 to 70 years and having undergone a full cervical spine CT scan for a reason other than an investigation of a cervical spine malformation or congenital malformation. The 25 men and 14 women showed no significant difference for mean age. The exclusion criteria of the patients were pathological conditions of the cervical spine (e.g. Klippel-Feil syndrome, rheumatoid arthritis, tumors, infections, upper cervical spine trauma, or instrumentation) and insufficient radiological examinations for the proposed measurements.

Points and lines of the upper cervical vertebrae, measured parameters and abbreviations are shown in Table I. Measurements of parameters were evaluated by CT for each patient (Figure 1A,B).

\section{CT Scan Measurements}

The images were obtained on a 128-row multidetector CT (MDCT) scanner (Philips Ingenuity Core 128, Philips Medical System, Best, Netherlands), using a rotation time of $500 \mathrm{msec}$, tube voltage of $100 \mathrm{kV}$, tube current of $180 \mathrm{~mA}$ and matrix of $512 \times 512$. Reconstruction of the images was performed into 1-mm-thick slices and the space between the slices was $0.5 \mathrm{~mm}$. CT scans of the patients were analyzed on the present bone window setting: length of $750 \mathrm{HU}$ and width of $2300 \mathrm{HU}$. Then, sagittal and coronal three-dimensional (3-D) reconstructions were performed. These images were ordered in an odd numbered arrangement, and the central image was used in the study. The images were reviewed on the radiology workstation. All measurements were performed using the picture archiving and communication system (PACS).

\section{Statistical Analysis}

Statistical analyses was performed using the Statistical Package for the Social Sciences version 16.0 (SPSS Inc.,
Chicago, Illinois). The normality of variables was tested with the one-sample Kolmogorov-Smirnov test. Statistical comparisons were made with the Independent Samples t-test accept right EC and the Mann-Whitney $U$ test was used for right EC. The results are expressed as mean $\pm S D$. A $p$ value $<0.05$ was considered statistically significant.

\section{- RESULTS}

1. Results of CT measurements are shown in Table II: Mi-SPA, Ma-SPA, Mi-EP, Ma-EP, HI, and HJ measurements were compared between males and females on both sides.

a. With the exception of Ma-EP on the left side, statistically significant differences were not found between males and females ( $p>0.05)$.

2. Results of CT measurements are shown in Table III: Following upper evaluation, male and female measurements were combined. Then, Mi-SPA, Ma-SPA, and Mi-EP measurements were compared for the right and left sides.

a. Except for Mi-SPA, statistically significant differences were not found between the right and left sides $(p>0.05)$.

3. Results of CT measurements are shown in Table IV:

a. Mean values of the parameters were combined for both gender and left and right sides.

\section{DISCUSSION}

The first two vertebrae have a complex structure. The articulation between them accounts for $12 \%$ of the flexion/ extension and $50 \%$ of the rotation $\left(47^{\circ}\right)$ of the upper vertebra (22). Because of the fact that intervertebral discs do not exist, the stability of this segment is provided mainly by ligaments. Many disorders such as trauma, tumors, rheumatoid arthritis, congenital, inflammatory, and infectious diseases can cause instability of the first two vertebrae (9). Recently, fixation techniques have provided more stability and safety in surgery (8).

The Gallie, Brooks-Jenkins, and Sonntag techniques that were performed by the way of a posterior approach have been used for many decades to achieve arthrodesis $(6,10)$. However, they have been associated with high fusion failure rates because of their limited stiffness in rotation and also the requirement for rigid postoperative immobilization (7). Different screw constructs for the first two vertebrae fixation are the Goel-Harms C1 lateral mass-C2 pedicle screw construct, the Wright $\mathrm{C} 1$ lateral mass-C2 translaminar (C1LM-C2TL) screw construct, and the $\mathrm{C} 1$ lateral mass-C2 (C1LM-C2) pars screw construct (8). In all these techniques, an intact posterior atlantal arch is usually necessary to secure a bone graft across $\mathrm{C} 1-\mathrm{C} 2$ for fusion. However, in certain patients, such as those with spina bifida or bone loss from prior surgeries, the posterior arch of $\mathrm{C} 1$ is deficient, which makes it difficult to use the posterior arch of $\mathrm{C} 1$ for placement of the graft. In this situation, an alternative fusion technique is necessary for the 

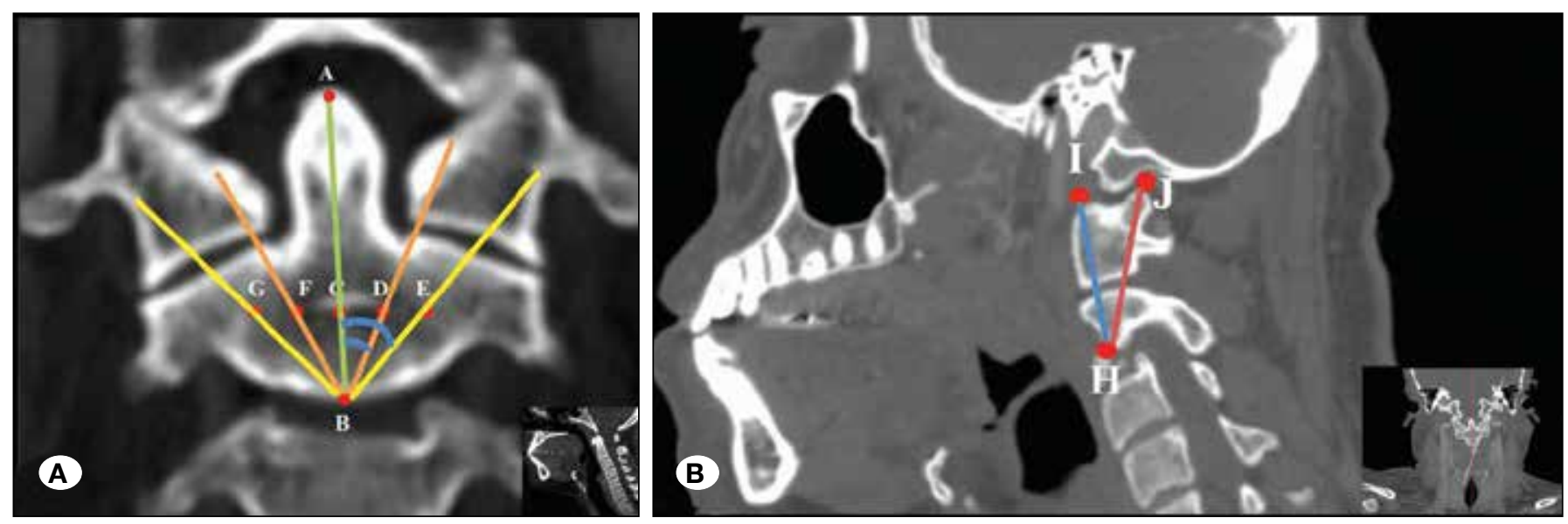

Figure 1: A) Coronal CT multiplanar reconstruction demonstrates points, angles, and lines. B) Sagittal CT multiplanar reconstruction demonstrates points and lines. See Table I for abbreviations.

Table I: Description of Points, Angles, and Lines Measured on Coronal and Sagittal Plane Cervical Vertebrae CT Reconstruction

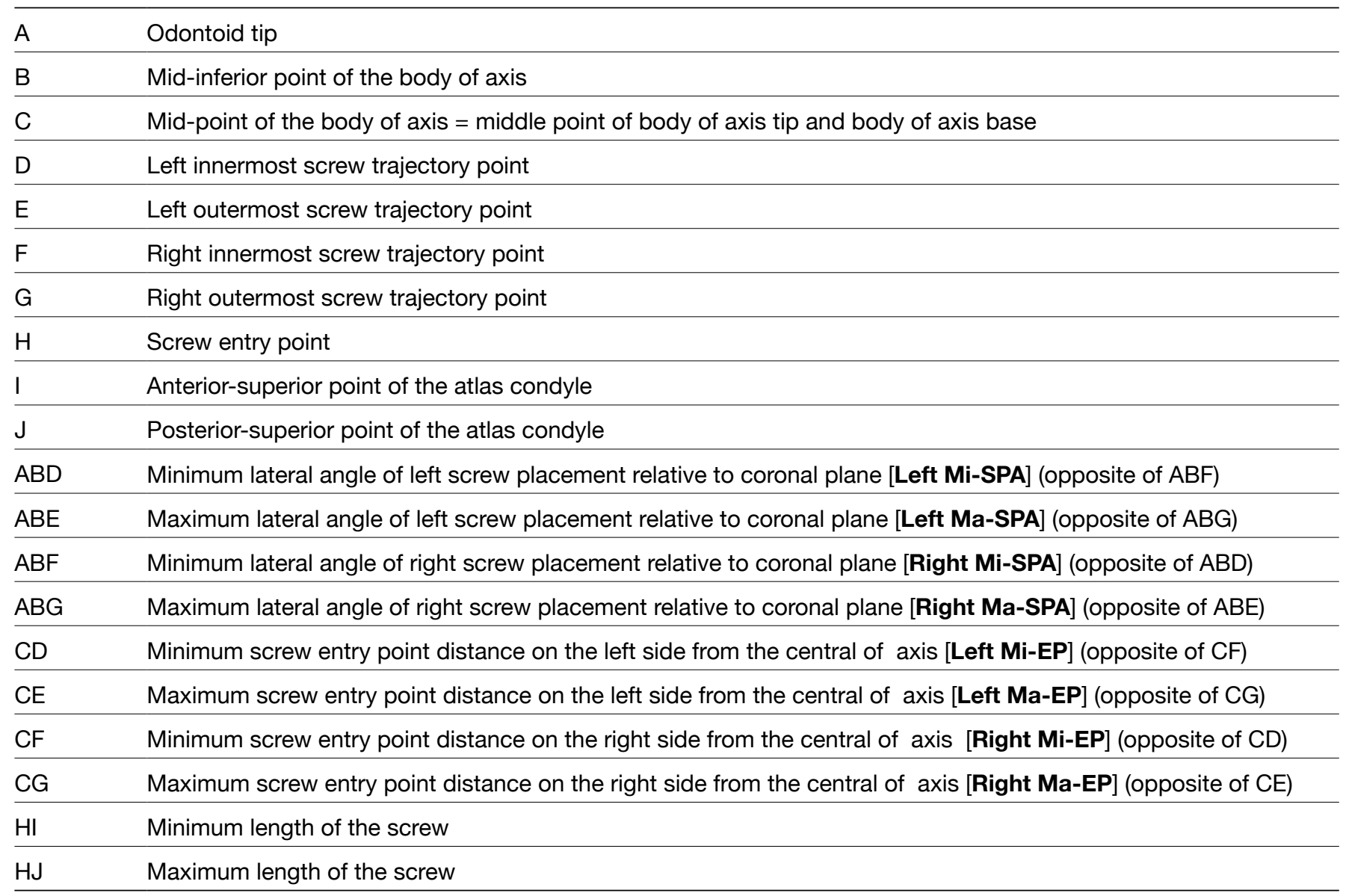

treatment of atlantoaxial instability (15). The first alternative method, that had been described to fix the C1-C2 articulation, was Simmons and du Toit's lateral atlantoaxial arthrodesis (20). Afterwards, a transarticular screw was placed through the C1-2 articular surfaces in another technique. Jeanneret and Magerl described this technique (11).
An anteriorly inserted transarticular screw fixation technique for the first two vertebrae has also been described $(4,14)$. Due to the fact that it reduces the need for additional posterior surgery, an anterior approach for transarticular fixation may be advantageous in some patients who need the latter surgery following a ventral approach $(14,21,24)$; for example, in cases 
Table II: Summary of Values

\begin{tabular}{|c|c|c|c|c|}
\hline & \multicolumn{2}{|c|}{ Female } & \multicolumn{2}{|c|}{ Male } \\
\hline & $\mathbf{R}$ & $\mathbf{L}$ & $\mathbf{R}$ & $\mathbf{L}$ \\
\hline Mi-SPA & $26.07 \pm 3.89$ & $24.71 \pm 4.38$ & $26.92 \pm 3.86$ & $24.80 \pm 3.87$ \\
\hline Ma-SPA & $40.64 \pm 4.67$ & $39.36 \pm 4.22$ & $42.76 \pm 4.69$ & $40.92 \pm 4.04$ \\
\hline Mi-EP & $3.92 \pm 0.92$ & $3.79 \pm 0.98$ & $3.76 \pm 1.05$ & $4.24 \pm 1.56$ \\
\hline Ma-EP & $8.00 \pm 1.66$ & $8.00 \pm 1.36$ & $8.72 \pm 1.24$ & $9.48 \pm 1.53$ \\
\hline $\mathrm{HI}$ & \multicolumn{2}{|c|}{$26.36 \pm 3.52$} & \multicolumn{2}{|c|}{$28.08 \pm 3.21$} \\
\hline HJ & \multicolumn{2}{|c|}{$27.00 \pm 3.35$} & \multicolumn{2}{|c|}{$29.28 \pm 3.54$} \\
\hline
\end{tabular}

*Significant at the 0.05 level.

Table III: Summary of Values

\begin{tabular}{ccc}
\hline & $\mathbf{R}$ & $\mathbf{L}$ \\
\hline Mi-SPA & $\mathbf{2 6 . 6 2} \pm \mathbf{3 . 8 4}$ & $\mathbf{2 4 . 7 7 \pm 4 . 0 0}$ \\
\hline Ma-SPA & $42.00 \pm 4.74$ & $40.36 \pm 4.12$ \\
\hline Mi-EP & $3.82 \pm 1.00$ & $4.08 \pm 1.38$ \\
\hline Ma-EP & $8.46 \pm 1.43$ & \\
\hline
\end{tabular}

*Significant at the 0.05 level.

Table IV: Summary of Values

\section{TOTAL}

\begin{tabular}{cc}
\hline MI-SPA & \\
\hline MA-SPA & $41.18 \pm 4.49$ \\
\hline MI-EP & $3.95 \pm 1.20$ \\
\hline MA-EP & \\
\hline HI & $27.46 \pm 3.39$ \\
\hline HJ & $28.46 \pm 3.60$ \\
\hline
\end{tabular}

*Significant at the 0.05 Level.

of odontoid resection. Furthermore, it may be an alternative for the situations where posterior screw placement would not be safe, unfeasible, or challenging due to unexpected conditions (14) or anatomical variations, for example aberrant or anomalous vertebral artery $(1,23)$, severe high-riding vertebral artery $(23,25)$, and narrow pars interarticularis (17). Anteriorly inserted transarticular screw fixation technique can also be used as an additional option when a previous dorsal approach has failed to provide enough stability (14). Moreover, this anterior approach technique may be an option for polytrauma, and respiratory-compromised (18) or hemodynamically vulnerable elderly patients (3), wherein a prone position may increase operative morbidity and/or mortality. Papers have shown that it has favorable early clinical outcomes (14) when compared with the dorsal approach (25) with high fusion rates and only minor complications (3), and less anatomic risk for the vertebral artery after this procedure was developed (5). Also, the biomechanical properties of ATAS are compatible with posterior fixation techniques such as posterior transarticular screws (19), and posterior C1 lateral mass screw combined with C2 pedicle screw/rod systems (13).

Our study aimed to analyze the possible screw angles, screw entry point, and screw length for ATAS fixation across the atlantoaxial joint in Turkish patients by using CT. In a review of the literature, it can be seen that few studies exist on this topic. Lu et al. measured 15 cadaver spines where the Mi-SPA values were $5.6^{\circ} \pm 1.6^{\circ}$ and $4.8^{\circ} \pm 1.8^{\circ}$ in males and females respectively; Ma-SPA values were $25.3^{\circ} \pm 2.6^{\circ}$ and $23.1^{\circ} \pm 3.8^{\circ}$ on males and females respectively; $H I$ values were $16.1 \pm 1.8$ $\mathrm{mm}$ and $14.7 \pm 1.5 \mathrm{~mm}$ on males and females respectively; and finally $\mathrm{HJ}$ values were $25.4 \pm 2.8 \mathrm{~mm}$ and $24.7 \pm 1.1 \mathrm{~mm}$ on males and females respectively (17). With exception of the HJ 28.46 $\pm 3.6 \mathrm{~mm}$ measurement, all of these measurements were not comparable with our study. The causes of the discordance may be due to variance between screw entry points, differences in measurements between patient race, and/or the differences in measurements due to the use of CT in our study. Recently, Ji et al. reported a study completed on 30 pairs of dried human $\mathrm{C} 1$ and $\mathrm{C} 2$ vertebrae where the Mi-SPA was $26.4^{\circ} \pm 3.1^{\circ}$ and $\mathrm{HJ}$ was $32.6 \pm 2.9 \mathrm{~mm}$. These findings were compatible with our measurements (12). On the other hand, the best screw entry point has not been previously evaluated comprehensively for ATAS fixation across the atlantoaxial joint. Surgeons may evaluate the radiological images that are needed for an anterior C1-C2 surgery before the operation (2). If the operation is an emergency surgery, using screws longer than $28.46 \pm 3.60 \mathrm{~mm}$ may be dangerous. In the present study, the aim of taking measurements before the surgery was to decrease the hazardous consequences; a screw angle not more than $41.18^{\circ} \pm 4.49^{\circ}$ on the coronal plane could be safer in order to protect the vertebral artery. Further studies using these radiological measurements during surgery for ATAS fixation across the atlantoaxial joint will be valuable. All spine surgeons should be aware of the anatomical relationship between the first cervical and second vertebra before ATAS fixation across the atlantoaxial joint, possibly limiting appropriate screw positioning. 


\section{CONCLUSION}

The possible screw angles for ATAS fixation across the atlantoaxial joint should be measured on coronal and sagittal CT multiplanar reconstruction images. These measurements may be useful for surgeons who need to perform the procedure of ATAS fixation across the atlantoaxial joint. In cases in which ATAS fixation across the atlantoaxial joint should be performed without first calculating the measurements, setting the screw angle not more than $41.18^{\circ} \pm 4.49^{\circ}$ on the coronal plane does not damage the vertebral artery while using screws shorter than $28.46 \pm 3.60 \mathrm{~mm}$ does not purchase the atlantoaxial joint.

\section{- REFERENCES}

1. Abou Madawi A, Solanki G, Casey AT, Crockard HA: Variation of the groove in the axis vertebra for the vertebral artery. Implications for instrumentation. J Bone Joint Surg Br 79: 820-823, 1997

2. Aebi M: Surgical treatment of upper, middle and lower cervical injuries and non-unions by anterior procedures. Eur Spine $J$ 19 Suppl 1: 33-39, 2010

3. Agrillo $U$, Mastronardi L: Acute combination fracture of atlas and axis: "triple" anterior screw fixation in a 92-year-old man: Technical note. Surg Neurol 65: 58-62, 2006

4. Apfelbaum RI, Lonser RR, Veres R, Casey A: Direct anterior screw fixation for recent and remote odontoid fractures. J Neurosurg 93 Suppl 2: 227-236, 2000

5. Barbour JR: Screw fixation and fractures of the odontoid process. S Aust Clin 5: 20-24 1971

6. Brooks AL, Jenkins EB: Atlanto-axial arthrodesis by the wedge compression method. J Bone Joint Surg Am 60:279284, 1978

7. Coyne TJ, Fehlings MG, Wallace MC, Bernstein M, Tator CH: C1-C2 posterior cervical fusion: Long-term evaluation of results and efficacy. Neurosurgery 37:688-692, 1995

8. Du JY, Aichmair A, Kueper J, Wright T, Lebl DR: Biomechanical analysis of screw constructs for atlantoaxial fixation in cadavers: A systematic review and meta-analysis. J Neurosurg Spine 22(2):151-161, 2015

9. Fried LC: Atlantoaxial fracture-dislocations. Failure of posterior C1 to C2 fusion. J Bone Joint Surg Br 55:490-496, 1973

10. Gallie WE: Fractures and dislocations of the cervical spine. Am J Surg 46: 495-499, 1939

11. Jeanneret B, Magerl F: Primary posterior fusion $\mathrm{C} 1 / 2$ in odontoid fractures: Indications, technique, and results of transarticular screw fixation. J Spinal Disord 5:464-475, 1992

12. Ji W, Zheng M, Tong J, Huang Z, Chen J, Qu D, Zhu Q: Feasibility and trajectory study of anterior transarticular crossing screw placement for atlantoaxial joint instability: A cadaveric study and description of a novel technique. Eur Spine J 24(12):2954-2960, 2015
13. Kim SM, Lim TJ, Paterno J, Hwang TJ, Lee KW, Balabhadra RS, Kim DH: Biomechanical comparison of anterior and posterior stabilization methods in atlantoaxial instability. $\mathrm{J}$ Neurosurg 100 Suppl Spine 3: 277-283, 2004

14. Koller H, Kammermeier V, Ulbricht D, Assuncao A, Karolus $S$, van den Berg B, Holz U: Anterior retropharyngeal fixation C1-C2 for stabilization of atlantoaxial instabilities: Study of feasibility, technical description and preliminary results. Eur Spine J 15:1326-1338, 2006

15. Li S, Ni B, Xie N, Wang M, Guo X, Zhang F, Wang J, Zhao W: Biomechanical evaluation of an atlantoaxial lateral mass fusion cage with C1-C2 pedicle fixation. Spine (Phila Pa 1976) 35(14):624-632, 2010

16. Li WL, Chi YL, Xu HZ, Wang XY, Lin Y, Huang QS, Mao FM: Percutaneous anterior transarticular screw fixation for atlantoaxial instability: A case series. J Bone Joint Surg Br 92: 545-549, 2010

17. Lu J, Ebraheim NA, Yang $H$, Heck BE, Yeasting RA: Anatomic considerations of anterior transarticular screw fixation for atlantoaxial instability. Spine 23: 1229-1235, discussion 1236, 1998

18. Reindl R, Sen M, Aebi M: Anterior instrumentation for traumatic C1-C2 instability. Spine 28: 329-333, 2003

19. Sen MK, Steffen T, Beckman L, Tsantrizos A, Reindl R, Aebi M: Atlantoaxial fusion using anterior transarticular screw fixation of C1-C2: Technical innovation and biomechanical study. Eur Spine J 14: 512-518, 2005

20. Simmons $\mathrm{EH}$, du Toit $\mathrm{G}$ Jr: Lateral atlantoaxial arthrodesis. Orthop Clin North Am 9(4):1101-1114, 1978

21. Wang J, Zhou Y, Zhang Z, Li C, Zheng W, Zhang Y: Minimally invasive anterior transarticular screw fixation and microendoscopic bone graft for atlantoaxial instability. Eur Spine J 21:1568-1574, 2012

22. White AA III, Punjabi MM: Clinical Biomechanics of the Spine. Philadelphia, PA: JB Lippincott, 1978: 66

23. Wright NM, Lauryssen C: Vertebral artery injury in C1-2 transarticular screw fixation: Results of a survey of the AANS/ CNS section on disorders of the spine and peripheral nerves. American Association of Neurological Surgeons/Congress of Neurological Surgeons. J Neurosurg 88: 634-640, 1998

24. Wu YS, Chi YL, Wang XY, Xu HZ, Lin Y, Mao FM, Huang QS, $\mathrm{Ni}$ WF: Microendoscopic anterior approach for irreducible atlantoaxial dislocation: Surgical techniques and preliminary results. J Spinal Disord Tech 23:113-120, 2010

25. Xu H, Chi YL, Wang XY, Dou HC, Wang S, Huang YX, Xu $\mathrm{HZ}$ : Comparison of the anatomic risk for vertebral artery injury associated with percutaneous atlantoaxial anterior and posterior transarticular screws. Spine J 12: 656-662, 2012 